\title{
RKCL4804
}

\section{PHOTODEGRADATION OF 4-CHLOROPHENOL BY UV/PHOTOCATALYSTS: THE EFFECT OF THE INTERPARTICLE ELECTRON TRANSFER PROCESS}

\author{
Xin-Hong Ou ${ }^{a}$, Chung-Hsin $W^{b^{*}}$ and Shang-Lien $\mathrm{Lo}^{\mathrm{a}}$ \\ ${ }^{a}$ Graduate Institute of Environmental Engineering, National Taiwan University, \\ Taipei 106, Taiwan, R.O.C. \\ ${ }^{\mathrm{b}}$ Department of Environmental Engineering, Da-Yeh University, 112, Shan-Jiau Rd., \\ Da-Tsuen, Chang-Hua 515, Taiwan, R.O.C.
}

Received May 20, 2005; in revised form August 19, 2005; accepted August 22, 2005

\begin{abstract}
This study explores the photodegradation of 4-chlorophenol (4-CP). Coupledphotocatalyst systems are tested to determine whether the interparticle electron transfer (IPET) process improves the photodegradation efficiency. $\mathrm{TiO}_{2}, \mathrm{ZnO}$ and $\mathrm{SnO}_{2}$ are selected as photocatalysts. In the single-photocatalyst test, $\mathrm{ZnO}$ exhibits the highest catalytic activity. The pseudo first-order rate constant of the coupledcatalyst system, $\mathrm{ZnO} / \mathrm{SnO}_{2}$, is approximately $22 \%$ higher than that of $\mathrm{ZnO}$; these rate constants are 0.95 and $0.78 \mathrm{~h}^{-1}$ at $\mathrm{pH} 11$, respectively.

Keywords: Photodegradation, interparticle electron transfer process, $\mathrm{TiO}_{2} ; \mathrm{ZnO}$, $\mathrm{SnO}_{2}$
\end{abstract}

\section{INTRODUCTION}

The problem of pollutants, particularly the serious environmental impact of their residues and the low efficiency of current remediation processes, has led

* Corresponding author. E-mail: chunghsinwu@yahoo.com.tw

0133-1736/2006/US\$20.00.

(c) Akadémiai Kiadó, Budapest. All rights reserved. 
to several attempts to find more efficient degradation alternatives. Numerous pollutants are decomposed by Advanced Oxidation Processes (AOPs) [1-4]. Heterogeneous photocatalysis has emerged as an efficient approach for purifying water $[2,5] . \quad \mathrm{TiO}_{2}$ and $\mathrm{ZnO}$ have been extensively investigated as heterogeneous photocatalysts, mainly because of their high capacity for degrading toxic and recalcitrant chemical species with fairly simple procedures. The applications of the photocatalytic process, mostly involving $\mathrm{TiO}_{2}$, have been extensively documented [2-5]. However, their photodegradation efficiency is restricted mainly by the recombination of the photogenerated holes and electrons. Photocatalysis involves chemical oxidation via a photogenerated hole from the semiconductor, so every recombination event leads to the loss of a hole that might otherwise have promoted degradation. Hence, a major focus of current photocatalysis research is to enhance the separation characteristics, thus improving photocatalytic efficiency. Various methods of increasing photo-efficiency have been proposed, including: (1) promoting photochemical degradation by including transition metals [6,7], and (2) exploiting the difference in the band gap between semiconductors with different energy potentials to retard the recombination of the generated photoelectrons and photoholes, thus increasing the hydroxyl radical production efficiency, in a process called IPET $[2,5,8,9]$. The coupled semiconductors with different redox energy levels for their corresponding conduction and valence bands can be employed to improve the charge separation efficiency, raising the charge lifetime and the efficiency of the interfacial charge transfer to the adsorbed substrate. Ultimately, this process significantly improves the photocatalytic performance of the semiconductors. This study elucidates the IPET effect using $\mathrm{TiO}_{2}, \mathrm{ZnO}$ and $\mathrm{SnO}_{2}$ as model photocatalysts, and 4-CP as the parent compound.

\section{MATERIALS AND METHOD}

Three semiconductor powders, $\mathrm{TiO}_{2}$ (Degussa P25), $\mathrm{ZnO}$ (Fluka) and $\mathrm{SnO}_{2}$ $(\mathrm{RDH})$, were used as photocatalysts. 4-CP (99\%) was purchased from Aldrich and was utilized without further treatment. Water was deionized and doubly distilled by Milli-Q.

All photodegradation experiments were conducted in a batch reactor. The reaction mixtures were illuminated under a UV lamp ( $8 \mathrm{~W}$, Philips), and the temperature was controlled at $25^{\circ} \mathrm{C}$ during the experimental period. Prior to the photocatalytic experiment, the suspension was prepared by mixing the desired concentration of 4-CP $\left(2 \times 10^{-4} \mathrm{M}\right)$ with various single and coupled photocatalysts, $\mathrm{TiO}_{2}, \mathrm{ZnO}, \mathrm{SnO}_{2}, \mathrm{TiO}_{2} / \mathrm{ZnO}, \mathrm{TiO}_{2} / \mathrm{SnO}_{2}, \mathrm{ZnO} / \mathrm{SnO}_{2}$ and 
$\mathrm{TiO}_{2} / \mathrm{ZnO} / \mathrm{SnO}_{2}(1.2 \mathrm{~g} / \mathrm{L})$. The slurry was stirred magnetically for $30 \mathrm{~min}$ in the dark to achieve an adsorption equilibrium for the substrate on the photocatalytic system, and hydrochloric acid or sodium hydroxide was added to maintain the desired $\mathrm{pH}$. The samples were centrifuged at $3000 \mathrm{rpm}$, and the supernatant was filtered through a $0.45 \mu \mathrm{m}$ filter membrane (Millipore). The concentration of 4-CP was analyzed using an HPLC (Waters 600E system) equipped with an UV-detector set at $274 \mathrm{~nm}$. UV-Vis (GBC Cintra 20) analyses were performed to obtain the light adsorption spectrum and band gap of each photocatalyst.

\section{RESULTS AND DISCUSSION}

Background experiments were conducted to confirm that 4-CP degradation was caused by the ambient environment or photodegradation. Hence, direct photolysis, evaporation and adsorption of 4-CP were tested, revealing that the disappearance of 4-CP was negligible under the background experimental conditions. Accordingly, 4-CP disappearance in the photocatalytic experiments could be attributed to complete photodegradation.

The specific surface areas of $\mathrm{TiO}_{2}, \mathrm{ZnO}$ and $\mathrm{SnO}_{2}$ powders were calculated as $54.2,4.6$ and $4.8 \mathrm{~m}^{2} / \mathrm{g}$, and the band gap energies were determined as 3.17 , 2.92 and $4.13 \mathrm{eV}$, respectively. The main wavelength of the UV lamp was approximately $365 \mathrm{~nm}$, decreasing the quantum efficiency of $\mathrm{SnO}_{2}$ with a wider band gap owing to poor utilization of UV light. The quantities applied in the test system were $0.5,0.8,1.0,1.3,1.6,1.9,2.2,3,4,6$ and $8 \mathrm{~g} / \mathrm{L}$ to optimize the concentration of catalyst required that maximizes the degradation rate. A genetic algorithm simulation on a software package (Evolve 5.0) was adopted to examine the effect of adding various quantities of catalyst on the photodegradation rate. Experiments were performed using various amounts of $\mathrm{TiO}_{2}$ at fixed $\mathrm{pH}$ and initial concentration of 4-CP. The genetic algorithm software found that the optimal quantity of photocatalyst was $1.2 \mathrm{~g} / \mathrm{L}$. Therefore, the photocatalyst dosage was set to $1.2 \mathrm{~g} / \mathrm{L}$ in all experiments.

Figures 1(a), (b) and (c) depict the photo-oxidation of 4-CP for each photocatalytic system in three aqueous media ( $\mathrm{pH} \mathrm{4,7}$ and 11). Table 1 lists the kapp values of 4-CP using single, coupled and sandwiched photocatalysts at $\mathrm{pH} \mathrm{4,} 7$ and 11. The reaction rates fit a first-order reaction model. Additionally, several investigations have demonstrated that the photodegradation rates can generally be approximated using first-order kinetics [10, 11]. Figure 1(a) indicates that $\mathrm{ZnO}$ is a poor photocatalyst in the oxidative degradation of 4-CP at $\mathrm{pH} 4$, since it corrodes in aqueous acidic media, as also showed in a previous study [12]. However, at $\mathrm{pH} 7$ and 11, $\mathrm{ZnO}$ exhibited better activity toward 4- 

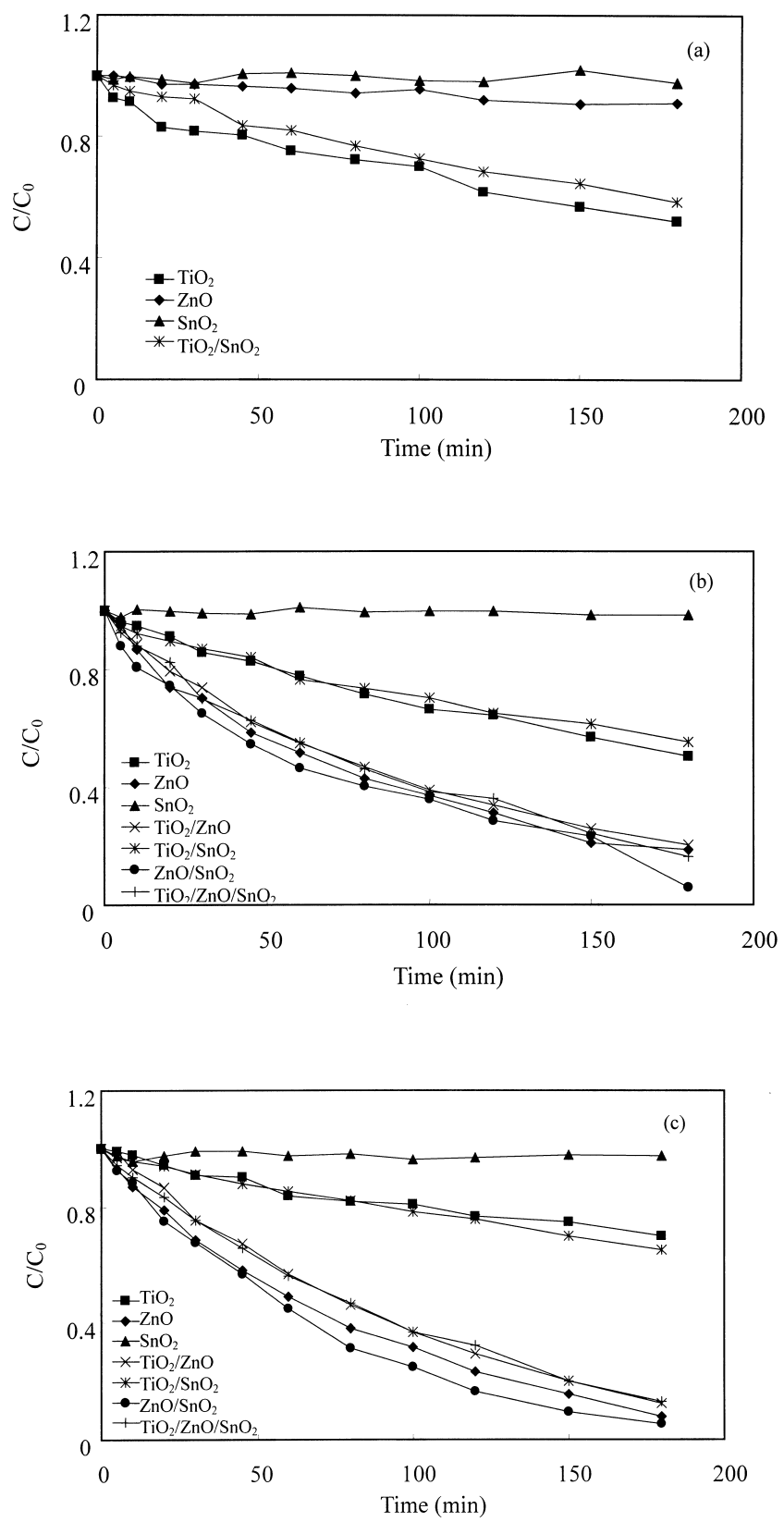

Fig. 1. Photodegradation of 4-CP with various photocatalytic systems at various $\mathrm{pH}$ values (a) $\mathrm{pH} \mathrm{4}$, (b) $\mathrm{pH} 7$ and (c) $\mathrm{pH} 11$ (photocatalyst $=1.2 \mathrm{~g} / \mathrm{L}, 4-\mathrm{CP}=$ $2 \times 10^{-4} \mathrm{M}$ and $25^{\circ} \mathrm{C}$ ) 
CP than did $\mathrm{TiO}_{2}$ by a factor of 3-7 for single-photocatalyst systems (Table 1). Also as expected, 4-CP did not degrade when $\mathrm{SnO}_{2}$ was irradiated with $365 \mathrm{~nm}$ UV light, since the UV source has insufficient energy to photoactivate $\mathrm{SnO}_{2}$. Meanwhile, the $\mathrm{k}_{a p p}$ values reveal that $\mathrm{ZnO}$ and $\mathrm{ZnO} / \mathrm{SnO}_{2}$ are the best catalytic systems at $\mathrm{pH} 7$ and 11, respectively. Thus, $\mathrm{ZnO}$ is a good photocatalyst for degrading 4-CP in alkaline aqueous media, suggesting that $\mathrm{ZnO}$ is highly active for 4-CP degradation. The single, coupled and sandwiched photocatalyst test results in Figs 1(a), (b) and (c) demonstrate that the reaction rate at $\mathrm{pH} 11$ is significantly higher than that at $\mathrm{pH} 7$ or $\mathrm{pH} 4$, except for the $\mathrm{TiO}_{2}$ and $\mathrm{TiO}_{2} / \mathrm{SnO}_{2}$ systems. This observation is consistent with the results obtained at high concentrations of photogenerated $\mathrm{OH}$ radicals in highly alkaline aqueous media $[2,5,9,12]$.

Table 1

Apparent first-order kinetics $\left(\mathrm{k}_{\text {app. }}, \mathrm{h}^{-1}\right)$ of the disappearance of 4-CP with various photocatalytic systems (photocatalyst $=1.2 \mathrm{~g} / \mathrm{L}, 4-\mathrm{CP}=2 \times 10^{-4} \mathrm{M}$ and $25^{\circ} \mathrm{C}$ )

\begin{tabular}{lcccccc}
\hline Systems & \multicolumn{2}{c}{$\mathrm{pH} \mathrm{4}$} & \multicolumn{2}{c}{$\mathrm{pH} 7$} & \multicolumn{2}{c}{$\mathrm{pH} \mathrm{11}$} \\
\hline & $\mathrm{k}$ & $\mathrm{r}$ & $\mathrm{k}$ & $\mathrm{r}^{2}$ & $\mathrm{k}$ & $\mathrm{r}^{2}$ \\
\hline $\mathrm{TiO}_{2}$ & 0.20 & 0.974 & 0.22 & 0.996 & 0.12 & 0.970 \\
$\mathrm{ZnO}$ & 0.03 & 0.921 & 0.57 & 0.992 & 0.78 & 0.988 \\
$\mathrm{SnO}_{2}$ & $\mathrm{~N} . \mathrm{D}$. & -- & $\mathrm{N} . \mathrm{D}$. & -- & $\mathrm{N} . \mathrm{D}$. & -- \\
$\mathrm{TiO}_{2} / \mathrm{ZnO}$ & -- & -- & 0.53 & 0.998 & 0.68 & 0.992 \\
$\mathrm{TiO}_{2} / \mathrm{SnO}_{2}$ & 0.17 & 0.991 & 0.19 & 0.988 & 0.14 & 0.997 \\
$\mathrm{ZnO}_{\mathrm{ZnOO}}$ & -- & -- & 0.56 & 0.900 & 0.95 & 0.994 \\
$\mathrm{TiO}_{2} / \mathrm{ZnO} / \mathrm{SnO}_{2}$ & -- & -- & 0.56 & 0.992 & 0.65 & 0.991 \\
\hline
\end{tabular}

Significantly, the catalytic ability of $\mathrm{TiO}_{2}$ was found to follow the order $\mathrm{pH} 7>\mathrm{pH} 4>\mathrm{pH} 11$. For $\mathrm{TiO}_{2}$ and $\mathrm{TiO}_{2} / \mathrm{SnO}_{2}$ systems at $\mathrm{pH} 4$ and 7 , the predominant species in the solution were the undissociated 4-CP molecules, rather than the corresponding anions, due to the $\mathrm{pK}_{\mathrm{a}}$ of $4-\mathrm{CP}\left(\mathrm{pK}_{\mathrm{a}}=9.2\right)$. Meanwhile, positively charged $\mathrm{TiO}_{2}$, owing to its surface acidity at $\mathrm{pH} 4$ and 7 , offers an appropriate prevailing condition for adsorption, under which the affinity between $\mathrm{TiO}_{2}$ and 4-CP is high, making the reaction rate higher than that at $\mathrm{pH}$ 11. Hence, 4-CP disappeared more slowly at $\mathrm{pH} 11$ than $\mathrm{pH} 7$, despite the increase in number of $\mathrm{OH}$ radicals in $\mathrm{TiO}_{2}$ surface, implying that the dominant role was the electrostatic repulsion between the negatively charged 4$\mathrm{CP}$ and the negatively charged $\mathrm{TiO}_{2}$ surface. Similar results were previously 
observed for the photodecomposition of 3-chlorophenol, since $\mathrm{HO}_{2}$ radicals form at low $\mathrm{pH}$, compensating for the decline in hydroxyl ion concentration [13].

The photodegradation rates of 4-CP at $\mathrm{pH} 11$ for the $\mathrm{TiO}_{2} / \mathrm{ZnO}, \mathrm{TiO}_{2} / \mathrm{SnO}_{2}$, $\mathrm{ZnO} / \mathrm{SnO}_{2}$ and $\mathrm{TiO}_{2} / \mathrm{ZnO} / \mathrm{SnO}_{2}$ systems were $0.68,0.14,0.95$ and $0.65 \mathrm{~h}^{-1}$, respectively. The $\mathrm{k}_{a p p}$ values for the $\mathrm{TiO}_{2}$ and $\mathrm{ZnO}$ single systems were 0.12 and $0.78 \mathrm{~h}^{-1}$. The experimental results indicate that the kinetics of the coupledphotocatalyst are superior to those of the single-photocatalyst systems, indirectly confirming the IPET effect. Galindo et al. [14] stated that $\mathrm{OH}$ radicals can be more easily generated in an alkaline solution by oxidizing more hydroxide ions on the surface of the photocatalyst, increasing the efficiency of the process. Moreover, scavenging electrons using a sacrificial electronacceptor reduces charge recombination, and thus increases the photoactivity of the catalysts. Hence, IPET improved efficiency only under alkaline conditions. However, the details of this phenomenon remain unknown.

At $\mathrm{pH} \mathrm{11,} \mathrm{the} \mathrm{experimental} \mathrm{results} \mathrm{agree} \mathrm{with} \mathrm{those} \mathrm{in} \mathrm{most} \mathrm{works,} \mathrm{showing}$ highly alkaline media facilitate photocatalysis $[2,5,9]$. The kinetic results of the $\mathrm{TiO}_{2} / \mathrm{SnO}_{2}$ and $\mathrm{ZnO} / \mathrm{SnO}_{2}$ systems demonstrate even greater activity toward 4-CP than in the single photocatalyst systems, $\mathrm{TiO}_{2}$ and $\mathrm{ZnO}$, since the redox energy levels of $\mathrm{TiO}_{2}$ and $\mathrm{SnO}_{2}$ differ significantly, as do those of $\mathrm{ZnO}$ and $\mathrm{SnO}_{2}$. The $\mathrm{TiO}_{2} / \mathrm{ZnO}$ and $\mathrm{TiO}_{2} / \mathrm{ZnO} / \mathrm{SnO}_{2}$ coupled and sandwiched photocatalyst systems at $\mathrm{pH} 7$ and 11 exhibited no increase in kinetic energy over of single $\mathrm{TiO}_{2}$ or $\mathrm{ZnO}$. The absolute energy levels of the valence and conduction bands played the most important role for the excited particles, explaining the possible IPET effect. The $\mathrm{TiO}_{2} / \mathrm{SnO}_{2}$ and $\mathrm{ZnO} / \mathrm{SnO}_{2}$ tests were significantly different in redox energy levels, and so exhibit better results concerning the IPET effect, particularly for the $\mathrm{ZnO} / \mathrm{SnO}_{2}$ tests, in which the difference between the conduction and valence bands was found to be large. This event is associated with the small difference between the conduction and valence bands of $\mathrm{TiO}_{2}$ and $\mathrm{ZnO}$. Accordingly, $\mathrm{TiO}_{2} / \mathrm{ZnO}$ tests may offer more opportunities for photo-electrons and photo-holes to recombine, reducing the IPET efficiency to below that in the $\mathrm{TiO}_{2} / \mathrm{SnO}_{2}$ and $\mathrm{ZnO} / \mathrm{SnO}_{2}$ tests.

In non-acidic aqueous media, $\mathrm{ZnO}$ was found to be a very efficient photocatalyst for the degradation of 4-CP, unlike $\mathrm{TiO}_{2}$, which catalyzed degradation 3-7 times more slowly than $\mathrm{ZnO}$. $\mathrm{SnO}_{2}$ exhibited almost no photocatalytic activity. However, when $\mathrm{TiO}_{2}$ or $\mathrm{ZnO}$ were coupled with $\mathrm{SnO}_{2}$ at $\mathrm{pH} 11,4-\mathrm{CP}$ oxidation was 17 and $22 \%$ faster than that obtained from $\mathrm{TiO}_{2}$ and $\mathrm{ZnO}$ systems, respectively. The experimental results reveal that $\mathrm{SnO}_{2}$ particles in the coupled photocatalyst systems $\left(\mathrm{TiO}_{2} / \mathrm{SnO}_{2}\right.$ and $\left.\mathrm{ZnO} / \mathrm{SnO}_{2}\right)$ are important for accepting the photogenerated electrons, and that the enhanced charge separation resulting from coupling two semiconductor systems with different energy levels improves the rate of photocatalytic degradation. 


\section{CONCLUSIONS}

The efficiency of 4-CP degradation depends strongly on the $\mathrm{pH}$ value and the incorporation of the semiconductors. This study indicates that the chemical kinetics associated with the IPET process indicate a decline in electron-hole recombination. However, this work also found that IPET does not provide all of the anticipated benefits to photocatalysis. The disappearance rate of 4-CP is higher in the coupled photocatalyst system than in single-photocatalyst systems when catalytic system is complex with a large difference between the redox energy levels of the corresponding conduction and valence bands, as in $\mathrm{ZnO} / \mathrm{SnO}_{2}$. Furthermore, the IPET effect only improved the photodegration rate in $\mathrm{pH}$ 11. The IPET effect provides an attractive mechanism for increasing the charge separation efficiency, increasing the lifetime of the charge carriers and improving the efficiency of the interfacial charge transfer to adsorbed substrates.

Acknowledgements. The authors would like to thank the National Science Council of the Republic of China for financially supporting this research under Contract No. NSC 93-2622-E-264-004-CC3.

\section{REFERENCES}

1. A. Sobczynski, L. Duczmal, W. Zmudzinski: J. Mol. Catal. A: Chem., 213, 225 (2004).

2. C.H. Wu: Chemosphere, 57, 601 (2004).

3. C.H. Wu, G.P. Chang-Chien, W.S. Lee: J. Hazard. Mater., 114, 191 (2004).

4. C.H. Wu, G.P. Chang-Chien, W.S. Lee: J. Hazard. Mater., 120, 257 (2005).

5. R.A. Doong, C.H. Chen, R.A. Maithreela, S.M. Chang: Water Res., 35, 2873 (2001).

6. A.D. Paola, E. Garcia-Lopez, S. Ikeda, G. Marci, B. Ohtani, L. Palmisano: Catal. Today, 78, 87 (2002).

7. U. Siemon, D. Bahnemann, J.J. Testa, D. Rodriguez, M.I. Litter, N. Bruno: J. Photochem. Photobiol. A: Chem., 148, 247 (2002).

8. S.C. Lo, C.F. Lin, C.H. Wu, P.H. Hsieh: J. Hazard. Mater., 114, 183 (2004).

9. N. Serpone, P. Maruthamuthu, P. Pichat, E. Pelizzatti, H. Hidaka: J. Photochem. Photobiol. A: Chem., 85, 247 (1995).

10. C.M. So, M.Y. Cheng, J.C. Yu, P.K. Wong: Chemosphere, 46, 905 (2002).

11. S. Sakthivel, B. Neppolian, M.V. Shankar, B. Arabindoo, M. Palanichamy, V. Murugesan: Solar Energy Mater. Solar Cells, 77, 65 (2003).

12. A.A. Khodja, T. Sehili, J.F. Pilichowski, P. Boule: J. Photochem. Photobiol. A: Chem., 141, 231 (2001).

13. Y. Ku, C.B. Hsieh: Water Res., 26, 1451 (1992).

14. C. Galindo, P. Jacques, A. Kalt: J. Photochem. Photobiol. A: Chem., 130, 35 (2000). 